\title{
The association of serum magnesium and bone mass density in men with chronic heart failure
}

\author{
Gomutput $\mathbf{P}^{1^{*}}$ and Leelawattana $\mathbf{R}^{2}$ \\ ${ }^{1}$ Department of Internal Medicine, Faculty of Medicine, Prince of Songkla University, Songkhla, Thailand \\ ${ }^{2}$ Division of Endocrinology and Metabolism, Department of Internal Medicine, Faculty of Medicine, Prince of Songkla University, Songkhla, Thailand
}

\begin{abstract}
Introduction: Heart failure has been found to be an independent risk factor for low bone mineral density, osteoporosis and osteoporotic fractures. Magnesium is a necessary component of trabecular bone. Its depletion impairs PTH release and end-organ response to PTH. Hypomagnesemia is common among chronic heart failure $(\mathrm{CHF})$, therefore hypomagnesemia could associate with low bone mass density (BMD) in CHF.
\end{abstract}

Objective: To study the association of serum magnesium level and BMD (using Z score) in CHF male.

Study design: Cross-sectional observation study.

Material and method: A prospective, cross-sectional study. One hundred CHF males aged 60 years or older with NYHA functional class II-III and identifiable comorbidities and medications used were recruited. Biochemical tests included $\mathrm{Cr}$, calcium, phosphate, albumin, magnesium and PTH closed to the day BMD measured.

Result: Twenty-two patients were hypomagnesemic, thirty-eight patients had low age-adjusted BMD. There was a trend of higher proportion of patients with hypomagnesemia in low BMD group than normal BMD group $(31.6 \%$ vs $16.1 \% \mathrm{p}=0.085)$. Spironolactone use was a protective factor of low bone mineral density and higher parathyroid hormone was independently associated with low BMD.

Conclusion: Hypomagnesemia and low BMD were prevalent in CHF. Hypomagnesemia showed only trend to associate with low BMD whereas using spironolactone was associated with better BMD.

\section{Introduction}

Heart failure is a global pandemic with a prevalence of over 26 million worldwide in 2014 and is associated with significant mortality, morbidity, and healthcare expenditures [1].

It is also an independent risk factor for osteoporosis and osteoporotic fractures [2,3]. In the cohort of 1,841 patients, 50 years of age and older with recent-onset heart failure, those with heart failure had lower total hip BMD, more previous fractures (21 vs. 13\%) and more incident major fractures ( $10 \mathrm{vs.} 5 \%$ ), compared to those without heart failure. The association persisted even after osteoporotic risk factors, comorbidities, medications and total hip BMD were adjusted [4]. Vitamin D inadequacy is found in a significant portion of patients with chronic heart failure and is associated with increase mortality and morbidity [5]. Previous study among patients with severe congestive heart failure found a substantial number of patients with low vitamin $D$ level, hyperparathyroidism, and low BMD.

However, in this study, BMD did not differ by vitamin D or PTH status [6]. Hypomagnesemia is common among chronic heart failure patients and associated with increased cardiovascular mortality [7]. According to Adamopoulous and collaterals, prevalence of hypomagesemia in chronic heart failure patients was $52 \%(828 / 1569)$ [8]. Magnesium homeostasis is crucial for bone health as $60 \%$ of total body magnesium is stored in the bone. Magnesium content of trabecular bone is significantly lower in subjects with osteoporosis. Its depletion also impairs PTH release and results in end-organ resistance for PTH [9].
Excluding the effect of sex hormones, age and other confounding factors on bone mineral density, this study aims to investigate is serum magnesium level a link to low bone mass density (using hip Z score) in chronic heart failure male.

\section{Method}

Study population: This study enrolled patients from Songklanagarind general medicine and cardiology outpatient clinic.

\section{Inclusion criteria were (all)}

Aged 60 years or older

Chronic (defined as clinically stable for at least 6 months) heart failure male patients

\section{NYHA functional class II-III}

Had identifiable comorbidities and medications used

${ }^{\star}$ Correspondence to: Gomutput P, Department of Internal Medicine, Faculty of Medicine, Prince of Songkla University, Songkhla, Thailand, E-mail: nowartap@hotmail.com

Key words: hypomagnesemia, bone mineral density, chronic heart failure

Received: November 01, 2018; Accepted: November 08, 2018; Published: November 12, 2018 


\section{Exclusion criteria were (any)}

Primary hyperparathyroidism

\section{Hypogonadism}

Chronic obstructive pulmonary disease (diagnosed from pulmonary function test or by a specialist)

Chronic kidney disease stage IV-V $($ GFR $<30 \mathrm{~mL} / \mathrm{min} / 1.73 \mathrm{~m} 2)$

Chronic liver disease (Child Pugh Score B, or C)

Known case of osteoporosis or prior history of fracture, malabsorption, known metabolic bone disease, excessive alcohol use ( $>$ 2 drinks/day) or corticosteroid use ( $>5 \mathrm{mg} /$ day for $>3$ months).

Initially patients with GFR $<60 \mathrm{~mL} / \mathrm{min} / 1.73 \mathrm{~m} 2$ were excluded, the protocol was substantially amended after 29 patients were recruited, based on the fact that PTH level begins to rise significantly at GFR less than $30 \mathrm{~mL} / \mathrm{min} / 1.73 \mathrm{~m} 2$.

The study was approved by Human Research Ethics Committee, faculty of medicine,

Prince of Songkla university.

Study design: Prospective cross-sectional study.

Sample size calculation: According to Adamopoulous and collaterals, prevalence of hypomagesemia in chronic heart failure patients was $52 \%(828 / 1569)$. For test of significance of 1 correlation with the expected correlation coefficient of 0.3, type I error rate of 1.96 and type II error rate of $0.84,100$ patients would be required.

Data collection: Data collection was done on age, weight, height, BMI, duration of heart failure, NYHA (II or III), types of heart failure (HFrEF or HFpEF), diabetes mellitus and hypertension, medication used including thiazide diuretics, loop diuretics, potassium sparing diuretics, ACEIs, ARBs, betablockers, nitric oxide, proton pump inhibitors, anticoagulants, digoxin, amiodarone, statins, and prokinetics

Blood test for $\mathrm{BUN}, \mathrm{Cr}, \mathrm{Na}, \mathrm{HCO} 3$, calcium, phosphate, magnesium, albumin and PTH were collected in fasting state. Bone mineral density was measured by dual energy x-ray absorptiometry using Lunar prodigy bone densitometer. In this study hypomagnesemia was defined as serum magnesium $<16 \mathrm{mg} / \mathrm{L}(0.64 \mathrm{mmol} / \mathrm{L})$ and low $\mathrm{BMD}$ was defined as $\mathrm{Z}$ score of femur $<0$.

Statistical analyses: Descriptive data for patients' characteristics presented as $\mathrm{n}(\%)$ were compared by chi square or fisher exact tests. Continuous data presented as mean \pm SD or median \pm IQR were compared with T-tests or Wilcoxon Rank sum tests. Univariate and multivariable regression analyses were performed to identify factors associated with low BMD and low magnesium. Statistics program RStudio was used for all analyses with the significance level of $\mathrm{p}<0.05$.

\section{Result}

Total 104 patients were included. Three were excluded due to missing data and one was excluded due to GFR $<30$. Prevalence of hypomagnesemia in this study was 22/100 and low BMD was 38/100. Characteristics of patients in the low BMD group ( $\mathrm{Z}$ score femur $<0$ ) and normal BMD group ( $Z$ score femur $>=0$ ) were illustrated in Tables 1 and 2 .

There was a trend of higher proportion of patients with hypomagnesemia in low BMD group than normal BMD group $(\mathrm{p}=0.085)$. Using BMD Tscore, 7 patients had osteoporosis, 26 patients had osteopenia and 67 patients had normal BMD.

Patients with low BMD weigh lower, have lower BMI, suffered longer duration of heart failure, have higher serum sodium and less prescribed with potassium sparing diuretic (spironolactone in this study) than patients with normal BMD. Furthermore, longer duration of heart failure, higher serum sodium and higher GFR are independent risk factors of hypomagnesemia.

According to multiple regression analysis of factors that showed trends to significance $(\mathrm{p}<0.1)$, serum magnesium, calcium, phosphate, parathyroid hormone and GFR, we found that potassium sparing diuretic use was a protective factor of low BMD and higher parathyroid hormone was independently associated with low BMD.

\section{Discussion}

To our knowledge, this is the first study to determine possible correlation between low serum magnesium level and low BMD in chronic heart failure male patients. In this prospective cross-sectional study, we excluded possible confounders of BMD such as sex, age, known metabolic bone diseases and steroid used, limiting data collection to male patients with chronic heart failure.

The prevalence of patients with low Zscore in this study was 38\%, compatible with $40 \%$ prevalence of osteoporosis (Tscore 2.5) in large population-based cohort study in 2012 [4]. This finding signifies high prevalence of osteoporosis among patients with congestive heart failure. There was a trend to significance $(\mathrm{p}=0.085)$ of low magnesium level in low BMD group. We did not measure the spine BMD because of the high probability of atherosclerosis of aorta, degenerative spine and collapse vertebrae in this age group, which may mask osteoporosis, and hip BMD was chosen instead. We would like to see the effect of magnesium on bone density independent of age, so $\mathrm{Z}$ score was used.

Our finding of significantly higher potassium sparing diuretic (aldosterone antagonist) used in normal BMD Z-score group supports previous data of aldosterone involvement in bone metabolism by its direct effect via mineralocorticoid receptors on osteocytes, osteoblasts, and osteoclasts and by secondary hyperparathyroidism from urinary and fecal calcium loss $[10,11,12]$.

Our population had a significant number of hyperparathyroidism of unknown cause (38\%). We did not study the cause of hyperparathyroidism, but it is very likely that hyperparathyroidism is secondary. The renal function among this group was not worse than stage 4 CKD but the causes of hyperparathyroidism such as vitamin D deficiency were not studied.

Interestingly, when analyzing all significant factors, potassium sparing diuretics and levels of PTH are predictors of BMD. This knowledge can lead to further studies focusing on these correlations. There are some limitations of this study. First, our population had lower than expected rate of hypomagnesemia which could be from different cut off point of hypomagnesemia $(25 \mathrm{mg} / \mathrm{L}$ in study by Adamopoulos et al. in 2009 [8] and $16 \mathrm{mg} / \mathrm{L}$ in our study). Another explanation is that Oriental diet (rich in fruits and vegetables), contains more magnesium than Western diet and several factors such as chronic diseases, alcohol consumption, medications and stress can differ magnesium level between population studied. We did not perform the gold standard for the diagnosis of magnesium deficiency, magnesium load test. The majority of patients were in NYHA classification II, same as vast 
Table 1. Characteristics of patients with low BMD and normal BMD

\begin{tabular}{|c|c|c|c|c|}
\hline & All patients, $N=100$ & $\begin{array}{l}\text { Low BMD group } \\
(\mathrm{Z} \text { femur }<\mathbf{0}) \mathbf{N}=\mathbf{3 8}\end{array}$ & $\begin{array}{l}\text { Normal BMD group } \\
(\mathrm{Z} \text { femur }>=0) \mathrm{N}=62\end{array}$ & p-value \\
\hline Age & $72.65(66.8-77)$ & $74(68.5-77.95)$ & $69.8(65.95-76.5)$ & 0.11 \\
\hline BW & $64.84 \pm 12.33$ & $60.37 \pm 11.94$ & $67.57 \pm 11.66$ & 0.004 \\
\hline BMI & $24.81 \pm 4.26$ & $23.03 \pm 3.58$ & $25.91 \pm 4.24$ & 0.0008 \\
\hline HFrHF & $81(81 \%)$ & $32(84.21 \%)$ & $49(79.04 \%)$ & 0.366 \\
\hline Duration of heart failure (year) & $3(1-5.25)$ & $4(2-6)$ & $2(0.5-5.5)$ & 0.043 \\
\hline NYHA class III & $38(38 \%)$ & $11(28.94 \%)$ & $9(14.51 \%)$ & 0.643 \\
\hline Diabetes & $31(31 \%)$ & $9(23.68 \%)$ & $22(35.48 \%)$ & 0.309 \\
\hline Hypertension & $38(38 \%)$ & $16(42.1 \%)$ & $22(35.48 \%)$ & 0.774 \\
\hline Thiazide & $4(4 \%)$ & $2(5.26 \%)$ & $2(3.22 \%)$ & 0.634 \\
\hline Loop diuretic & $59(59 \%)$ & $21(55.26 \%)$ & $38(61.29 \%)$ & 0.421 \\
\hline Aldactone & $29(29 \%)$ & $6(15.78)$ & $23(37.1 \%)$ & 0.012 \\
\hline ACEI & $31(31 \%)$ & $8(21 \%)$ & $23(37.1 \%)$ & 0.144 \\
\hline ARB & $27(27 \%)$ & $12(31.57 \%)$ & $15(24.19 \%)$ & 0.565 \\
\hline Betablocker & $75(75 \%)$ & $26(68.42 \%)$ & $49(79 \%)$ & 0.341 \\
\hline Nitrate & $33(33 \%)$ & $13(34.21 \%)$ & $20(32.26 \%)$ & 1 \\
\hline Statin & $85(85 \%)$ & $33(86.84 \%)$ & $52(83.87 \%)$ & 0.908 \\
\hline Anticoagulant & $40(40 \%)$ & $20(52.63 \%)$ & $20(32.26 \%)$ & 0.165 \\
\hline Digoxin & $11(11 \%)$ & $5(13.16 \%)$ & $6(9.68 \%)$ & 0.744 \\
\hline Cordarone & $2(2 \%)$ & $1(2.63 \%)$ & $1(1.61 \%)$ & 1 \\
\hline PPI & $57(57 \%)$ & $26(68.42 \%)$ & $31(50 \%)$ & 0.213 \\
\hline Prokinetic & $5(5 \%)$ & $5(13.15 \%)$ & 0 & 0.007 \\
\hline Hypomagnesemia & $22(22 \%)$ & $12(31.57 \%)$ & $10(16.13 \%)$ & 0.085 \\
\hline $\mathrm{Mg}$ & $\begin{array}{c}19.79 \\
(16.3-21.6)\end{array}$ & $\begin{array}{c}19.3 \\
(15.59-21.3)\end{array}$ & $\begin{array}{c}20 \\
(16.65-21.75)\end{array}$ & 0.184 \\
\hline $\mathrm{Ca}$ & $9.2(9-9.4)$ & $9.2(8.9-9.4)$ & $9.3(9-9.4)$ & 0.428 \\
\hline PO4 & $3(2.68-3.33)$ & $2.9 \pm 0.565$ & $3.06 \pm 0.5$ & 0.143 \\
\hline Alb & $4.2(3.9-4.5)$ & $4.1(3.9-4.4)$ & $4.3(4-4.5)$ & 0.113 \\
\hline PTH & $55.98(41.46-75.23)$ & $\begin{array}{c}63.02 \\
(44.64-80.46)\end{array}$ & $\begin{array}{c}55.54 \\
(38.84-71.9)\end{array}$ & 0.069 \\
\hline $\mathrm{PTH}>65 \mathrm{pg} / \mathrm{ml}(\mathrm{N}=38)$ & $38(38 \%)$ & $18(47.36 \%)$ & $20(32.25 \%)$ & \multirow{2}{*}{0.194} \\
\hline $\mathrm{PTH}<=65 \mathrm{pg} / \mathrm{ml}(\mathrm{N}=62)$ & $62(62 \%)$ & $20(52.63 \%)$ & $42(67.74 \%)$ & \\
\hline $\mathrm{Na}$ & $140.65(138.9-141.93)$ & $\begin{array}{c}141.3 \\
(138.9-142.5)\end{array}$ & $140(138.35-141.5)$ & 0.035 \\
\hline $\mathrm{HCO} 3$ & $25.4 \pm 2.65$ & $25.72 \pm 2.64$ & $25.51 \pm 2.64$ & 0.703 \\
\hline GFR 30-44 (N=13) & $13(13 \%)$ & $3(7.8 \%)$ & $10(16.1 \%)$ & \multirow{3}{*}{0.39} \\
\hline GFR 45-59 $(\mathrm{N}=24)$ & $24(24 \%)$ & $8(21.1 \%)$ & $16(25.8 \%)$ & \\
\hline GFR $>=60(\mathrm{~N}=63)$ & $63(63 \%)$ & $27(71.1 \%)$ & $36(58.1 \%)$ & \\
\hline
\end{tabular}

Table 2. Multiple regression analysis of factors associated with low BMD

\begin{tabular}{|l|c|c|c|}
\hline & Odd ratio & p-value & 0.615 \\
\hline Mg & 1.04 & $0.051,1.33$ \\
\hline Hypomagnesemia & 2.71 & 0.327 & 0.454 \\
\hline BMI & 0.72 & 0.779 \\
\hline BW & 1.05 & $0.3-1.7$ \\
\hline Duration & 1.18 & $0.75-1.46$ \\
\hline K.sparing & 0.13 & 0.008 & $0.97-1.44$ \\
\hline Na & 1.04 & 0.752 & $0.03-0.58$ \\
\hline PTH & 1.02 & 0.04 & $0.81-1.33$ \\
\hline Ca & 1.36 & 0.684 \\
\hline PO4 & 0.81 & 0.684 \\
\hline GFR & 1.04 & 0.096 \\
\hline
\end{tabular}

majority of patients in clinical practice, however, we limited our study only to males thus this information could not represent the whole group of chronic heart failure patients but may represent the majority of cases. Lastly, we did not explore the prevalent fracture, so the prevalence of established osteoporosis is unstudied.

In conclusion, male patients with stable chronic heart failure are at higher risk of low bone mass. Hyperparathyroidism, presumably secondary hyperparathyroidism is related and potassium sparing diuretic is a protective factor. Hypomagnesemia is prevalent and might link to low BMD in this population. The larger population and more studies are needed. Provided that hypomagnesemia should link to low bone mass in chronic heart failure, further studies should be done to determine whether replacing magnesium will prevent bone loss. 


\section{References}

1. Ponikowski P, Anker SD, AlHabib KF, Cowie MR, Force TL, et al. (2014) Heart failure: preventing disease and death worldwide. ESC Heart Fail 1: 4-25. [Crossref]

2. Aluoch AO, Jessee R, Habal H, Garcia-Rosell M, Shah R, et al. (2012) Heart failure as a risk factor for osteoporosis and fractures. Curr Osteoporos Rep 10: 258-269. [Crossref]

3. Jankowska EA, Jakubaszko J, Cwynar A, Majda J, Ponikowska B, et al. (2009) Bone mineral status and bone loss over time in men with chronic systolic heart failure and their clinical and hormonal determinants. Eur J Heart Fail 11: 28-38. [Crossref]

4. Majumdar SR, Ezekowitz JA, Lix LM, Leslie WD (2012) Heart failure is a clinically and densitometrically independent risk factor for osteoporotic fractures: populationbased cohort study of 45,509 subjects. J Clin Endocrinol Metab 97: 1179-1186. [Crossref]

5. Pourdjabbar A, Dwivedi G, Haddad H (2013) The role of vitamin D in chronic heart failure. Curr Opin Cardiol 28: 216-222. [Crossref]

6. Shane E, Mancini D, Aaronson K, Silverberg SJ, Seibel MJ, et al. (1997) Bone mass, vitamin $\mathrm{D}$ deficiency, and hyperparathyroidism in congestive heart failure. $\mathrm{Am} \mathrm{J}$ Med 103: 197-207. [Crossref]
7. Angkananard T, Anothaisintawee T, Eursiriwan S, Gorelik O, McEvoy M, et al. (2016) The association of serum magnesium and mortality outcomes in heart failure patients: A systematic review and meta-analysis. Medicine (Baltimore) 95: e5406. [Crossref]

8. Adamopoulos C, Pitt B, Sui X, Love TE, Zannad F, et al. (2009) Low serum magnesium and cardiovascular mortality in chronic heart failure: a propensity-matched study. Int J Cardiol 136: 270-277. [Crossref]

9. Swaminathan R (2003) Magnesium metabolism and its disorders. Clin Biochem Rev 24: 47-66. [Crossref]

10. Fumoto T, Ishii KA, Ito M, Berger S, Schütz G, et al. (2014) Mineralocorticoid receptor function in bone metabolism and its role in glucocorticoid-induced osteopenia. Biochemical Biochem Biophys Res Commun 447: 407-412. [Crossref]

11. Salcuni AS, Carnevale V, Battista C, Palmieri S, Eller-Vainicher C, et al. (2017) Primary aldosteronism as a cause of secondary osteoporosis. Eur J Endocrinol 177 431-437. [Crossref]

12. Tomaschitz A, Ritz E, Pieske B, Rus-Machan J, Kienreich K, et al. (2014) Aldosterone and parathyroid hormone interactions as mediators of metabolic and cardiovascular disease. Metabolism 63: 20-31. [Crossref]

Copyright: $\odot 2018$ Gomutput P. This is an open-access article distributed under the terms of the Creative Commons Attribution License, which permits unrestricted use, distribution, and reproduction in any medium, provided the original author and source are credited. 